\title{
Coulisses
}

Revue de théâtre

\section{La mode-spectacle ou le spectacle de la mode}

Manu-Xavier Bouchet, Viviane Millerand et Rédaction

\section{(2) OpenEdition \\ Journals}

Édition électronique

URL : http://journals.openedition.org/coulisses/1584

DOI : $10.4000 /$ coulisses. 1584

ISSN : 2546-9460

Éditeur

Presses universitaires de Franche-Comté

\section{Édition imprimée}

Date de publication : 1 novembre 1990

Pagination : $\mathrm{np}$

ISSN : $1150-594 \mathrm{X}$

\section{Référence électronique}

Manu-Xavier Bouchet, Viviane Millerand et Rédaction, « La mode-spectacle ou le spectacle de la mode », Coulisses [En ligne], 2 | Automne 1990, mis en ligne le 04 juillet 2017, consulté le 21 octobre 2019.

URL : http://journals.openedition.org/coulisses/1584; DOI : 10.4000/coulisses. 1584

Ce document a été généré automatiquement le 21 octobre 2019.

Coulisses 


\title{
La mode-spectacle ou le spectacle de la mode
}

\author{
Manu-Xavier Bouchet, Viviane Millerand et Rédaction
}

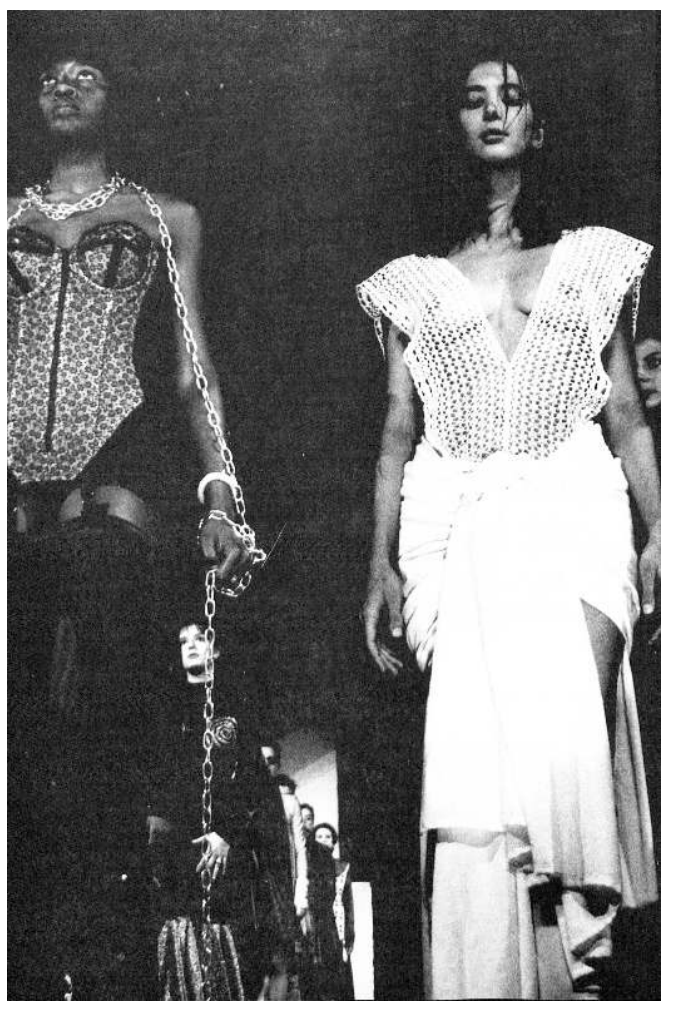

(c) Collectif Photo BVOJ 90.

\section{Cette fille est une erreur}

Dans le cadre de BVOJ 1989, trois stylistes avaient eu la possibilité de présenter leurs modèles. La manifestation avait été si bien reçue par le public qu'ils se sont groupés en 
association du nom de "En effeuillant la marguerite » et nous ont présenté, cette année encore, leurs collections. Le spectacle était composé de deux défilés, le premier étant celui de Viviane Milleran et d'Éric Bingler, le deuxième celui de Marion Duarte.

2 Les mannequins ont évolué sans rupture de rythme, valorisés par les décors de F. Gauthier et les diaporamas de C. Lopez.

\section{Viviane Milleran et Éric Bingler : la mode mystique}

3 Ils confrontent leurs idées et les réalisent ensemble. Ils ne se limitent pas à une conception particulière du vêtement parce que travailler dans le domaine de la mode implique qu'on suive plus ou moins les tendances du moment ou à tout le moins, que l'on s'inspire de celles qui correspondent le mieux à un état d'esprit. Ils ont ouvert une boutique rue des Granges, « Marylou sous la neige ».

4 Toutes les longueurs sont exploitées. La combinaison de sous-vêtement est devenue vêtement, présente sous différentes formes, ample ou moulante. Tous leurs modèles sont marqués de la même inspiration mystique et évoluent entre décadence et pureté, les accessoires variant de la chaîne à la croix.

\section{Marion Duarte : la femme fragile}

Elle conçoit et réalise seule ses modèles. Elle se réclame d'un style minimaliste, délibérément retenu et sobre, et recourt à la «non-couleur » : le blanc, le noir et à la rigueur le marron. Sa femme est à la fois digne et fragile, incapable d'extérioriser ses sentiments.

Philippe Josph a signé les photographies du catalogue qu'elle édite pour commercialiser ses modèles.

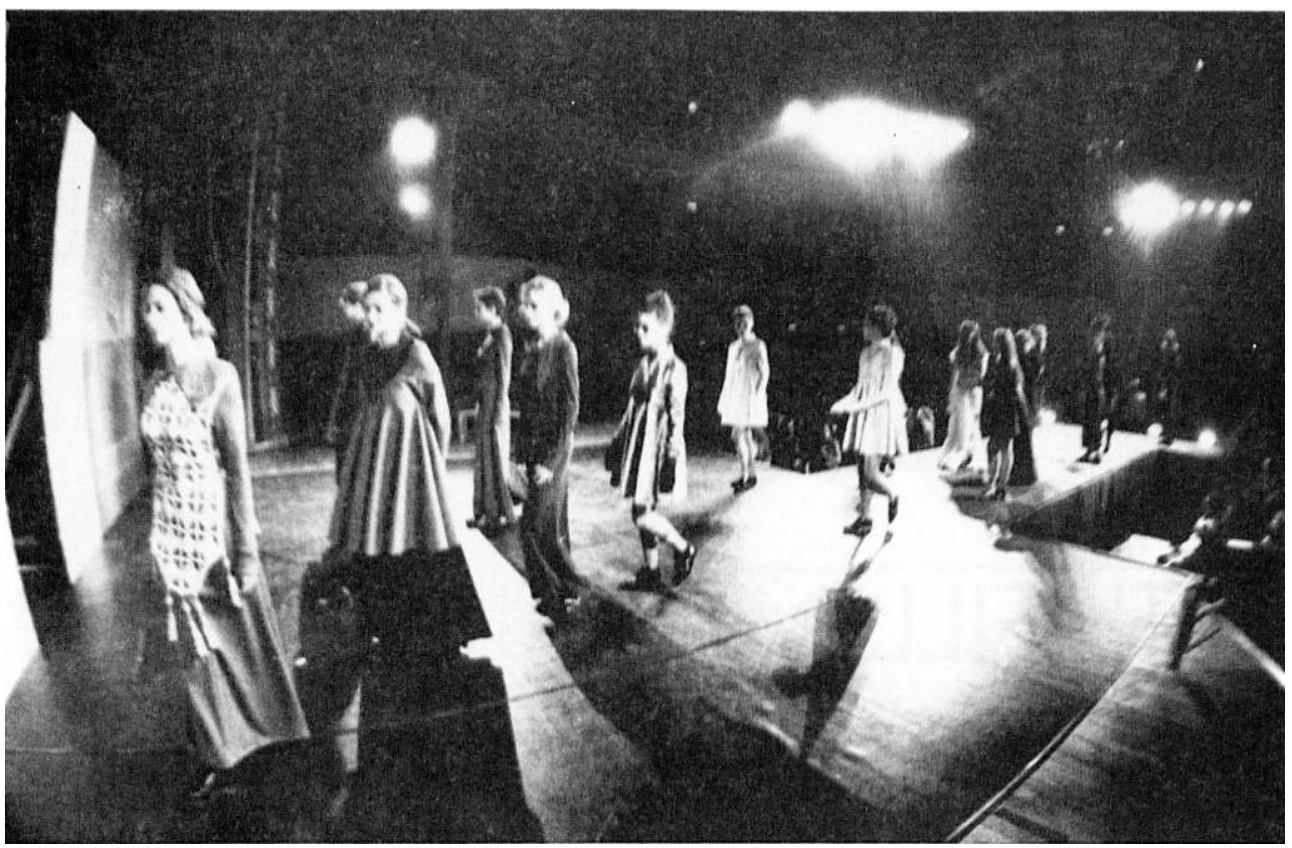

(c) Collectif Photo BVOJ 90. 


\section{Impressions d'un échantillonnage pseudo-représentatif de la population, hommes et femmes confondus de 19 à 60 ans environ...}

\section{On a aimé}

«... D’un point de vue général, je trouve cela sympa... »

« ... Le décor était à la hauteur des costumes. La musique religieuse et l'odeur d'encens donnait un ton sévère à tout le défilé... »

«... Les thèmes se suivent d'une manière logique : la décadence, le futurisme, la pureté. Les vêtements incarnent bien ces thèmes... »

10 «... La chorégraphie était très bien... »

11 «... La musique s'accordait bien avec les vêtements... »

12 « ... Les modèles étaient ravissants... » : « Ce qui m'a le plus plu ce sont les impers... », «... c'est une tenue en brun...»

\section{Réserves}

« ... D’un point de vue général, je pense qu'ils ne sont pas allés au fond de leur truc... »

«... Il y a un manque de mouvement. C'est le défaut des débutants... Il y a un manque évident de lumière... »

«... Le mélange du rouge et du noir du décor était trop expressif... »

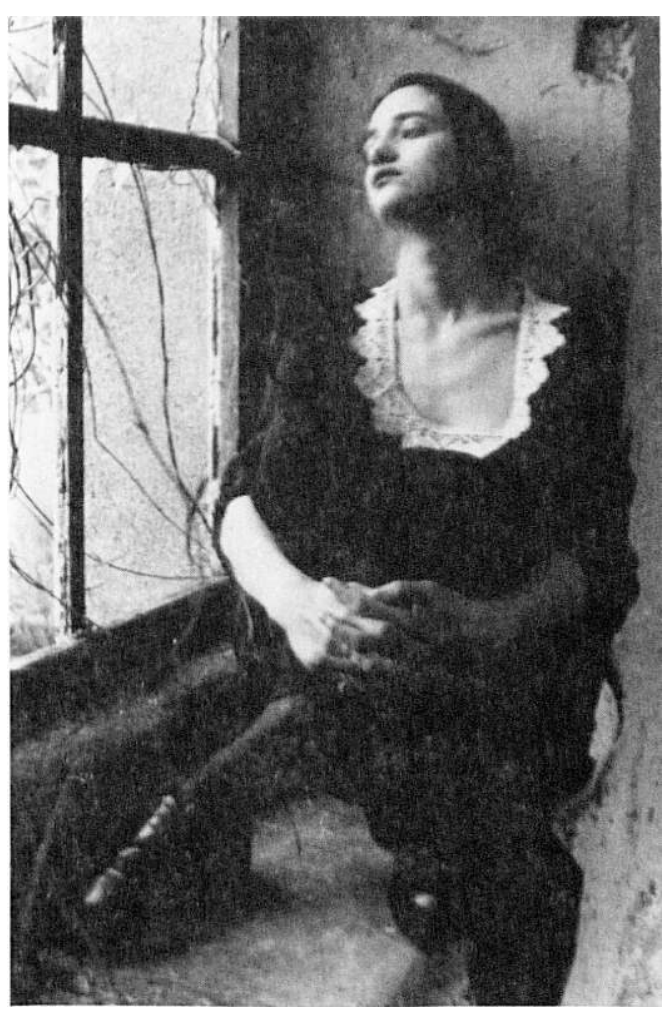

(c) Collectif Photo BVOJ 90. 


\section{Entretiens}

\section{Manu-Xavier Bouchet, peintre et décorateur}

Q. : Quel est ton rôle dans le spectacle?

M.-X. B. : Je me suis occupé des décors dans la première partie qui s'appelle « de la décadence à la pureté »: il y a trois thèmes, j'ai donc fabriqué et peint un triptyque composé de deux panneaux fixes de chaque côté du panneau central mobile. À la fin, il y a une machinerie avec un décor qui s'ouvre. J'ai voulu jouer dans la subtilité des teintes pour que les vêtements soient mis en valeur et que, néanmoins le décor puisse dire quelque chose. Pour le thème de la décadence, j'ai utilisé le rouge et le noir et peint des formes agressives afin d'accentuer les formes provocantes des vêtements renforcés par une chorégraphie nerveuse. Pour le thème " futurisme ", j'ai joué sur les contrastes blanc, gris et noir, il est plus question ici de valeur que de couleur; je suis plus un valoriste qu'un coloriste. J'ai néanmoins utilisé le vert et le marron dont j'ai pu tirer un effet que j'estime intéressant,

C'est un jeu d'équilibre : le décor peut être séparé par le milieu que ce soit dans la longueur ou dans la largeur, et cela permet, au cours des thèmes de déplacer la symétrie et d'arriver à une asymétrie totale, car pour moi, la pureté est quelque chose d'asymétrique. Tous les panneaux sont pleins, ils font tous deux mètres sur trois, mais le dernier est évidé au milieu, j'ai laissé un encart vide parce que la pureté se trouve là. Je ne peux pas peindre la pureté, je ne peux pas la montrer aux gens ; la pureté c'est quelque chose que les gens doivent prendre.

\section{Viviane Millerand, styliste de la $1^{\text {ère }}$ partie}

Q. : qu'avez-vous fait avant BVOJ ?

V. : cela fait quatre ans que je participe à BVOJ. Là, on vient de créer une boutique qui s'appelle « Marylou sous la neige ».

Q. : Pourquoi ce nom?

V. : c'est le titre d'une chanson de Gainsbourg, c'est un nom de boutique qui passe bien. Il exprime notre style de vêtement pour la boutique et son originalité.

\section{Une philosophie de la mode}

Les vêtements sont représentatifs d'une personnalité. On s'habille de telle façon pour affirmer sa personnalité. Nous nous opposons au conformisme, à la morosité. C'est un vêtement original qui permet à celles qui le portent de s'extérioriser.

V.: J'aime la matière brillante, et le velours aussi. Si j'avais les moyens, j'aimerais utiliser des matières plus originales comme Gaultier, c'est la seule possibilité d'innover totalement.

Pour la forme, on s'inspire et on réactualise des vêtements d'époques précédentes. 


\section{Impressions}

\section{Spectateur - 20 ans - à propos de la première partie}

Spectateur novice - que pouvait bien cacher cet intitulé «Spectacle autour de la Mode?»-, attiré par ce titre singulier cette fille est une erreur, j'ai pu découvrir un spectacle qui de par sa nouveauté, allait m'étonner.

Mis en confiance, dès le début, par un décor sobre, mais mystérieux et impressionnant, allié à une musique profonde, j'ai pu voir danser et jouer des actrices au rythme de cette musique captivant mon attention.

Si j'ai pu vite me rendre compte que les vêtements présentés seraient difficilement portés dans la rue - effaçant dans mon esprit le terme «mode »-, je les ai trouvés en accord parfait avec la musique et la chorégraphie, donnant son sens à la soirée comme spectacle. Les mouvements saccadés, les yeux dans le vague, les attitudes impersonnelles des filles donnaient dans une pénombre savamment entretenue quelque chose de surréel, fantastique à la scène. J'ai cru voir une certaine évolution dans le style des vêtements et dans la musique que j'aurais aimé retrouver aussi dans l'attitude des personnages; ce que je regrette aussi c'est le manque évident d'entraînement gestuel et rythmique de quelques mannequins qui cassait l'effet comme un réveil brutal brisant un rêve heureux.

\section{Spectatrice - 20 ans - à propos de la deuxième partie}

Sur un écran géant, au centre d'un panneau peint, passaient des diapositives sur lesquelles apparaissaient le sable : la matière brute, l'étendue vierge, et sur le sable, une empreinte : la vie, une présence et sur l'empreinte, le pied - la nudité du corps et les pieds d'une femme : la beauté, la sensualité puis sur son corps, le vêtement : la matière travaillée par l'homme.

Images d'une fille fragile et distante... Le genre de fille que voulait mettre en valeur la styliste. Un mystère, une pureté, une beauté émanaient de cette statue de chair, ainsi qu'une idée de légèreté que l'on retrouvait dans la chorégraphie, sur scène. Une empreinte, un parfum, un regard, puis un frôlement, une démarche, une ronde: provocation ou mélancolie? gravité ou insouciance? rêve ou réalité ? La vie, le temps d'une comptine !... Et pour finir, une pluie de riz, un tourbillon de visages aux sourires angéliques... 